\title{
Modelling flood damages under climate change conditions - a case study for Germany
}

\author{
F. F. Hattermann ${ }^{1}$, S. Huang ${ }^{1}$, O. Burghoff ${ }^{2}$, W. Willems ${ }^{3}$, H. Österle ${ }^{1}$, M. Büchner ${ }^{1}$, and Z. Kundzewicz ${ }^{1,4}$ \\ ${ }^{1}$ Potsdam Institute for Climate Impact Research (PIK), Potsdam, Germany \\ ${ }^{2}$ German Insurance Association (GDV), Berlin, Germany \\ ${ }^{3}$ Ingenieurhydrologie, Angewandte Wasserwirtschaft und Geoinformatik (IAWG), Ottobrunn, Germany \\ ${ }^{4}$ Institute for Agricultural and Forest Environment, Polish Academy of Sciences, Poznan, Poland \\ Correspondence to: F. F. Hattermann (hattermann@pik-potsdam.de)
}

Received: 15 September 2011 - Revised: 11 August 2014 - Accepted: 18 August 2014 - Published: 2 December 2014

\begin{abstract}
The aim of the study is to analyze and discuss possible climate change impacts on flood damages in Germany. The study was initiated and supported by the German insurance sector whereby the main goal was to identify general climate-related trends in flood hazard and damages and to explore sensitivity of results to climate scenario uncertainty. The study makes use of climate scenarios regionalized for the main river basins in Germany. A hydrological model (SWIM) that had been calibrated and validated for the main river gauges, was applied to transform these scenarios into discharge for more than 5000 river reaches. Extreme value distribution has been fitted to the time series of river discharge to derive the flood frequency statistics. The hydrological results for each river reach have been linked using the flood statistics to related damage functions provided by the German Insurance Association, considering damages on buildings and small enterprises. The result is that, under the specific scenario conditions, a considerable increase in flood related losses can be expected in Germany in future, warmer, climate.
\end{abstract}

\section{Introduction}

The latest report of the International Panel on Climate Change (IPCC, 2013) concluded that "since 1950, changes have been observed throughout the climate system: the atmosphere and ocean have warmed" and that "observed changes are unusual or unprecedented on time scales of decades to millennia". The climate change debate has triggered many studies of climate-change impacts on hydrological processes and water resources, being among the main concerns in Europe (Eisenreich, 2005; Lehner et al., 2006; Hattermann et al., 2008a; Arnell, 1999). The majority of studies investigate impacts in terms of water supply and changes in seasonality, while less studies deal with impacts on extremes (Dankers and Feyen, 2009; Kropp and Schellnhuber, 2010; Menzel and Burger, 2002). This is partly so because climate models are by their very nature constructed to simulate mean changes in climate conditions, and precipitation is only a secondary process in global climate models (GCMs) (Wilby et al., 1999). In order to produce climate information of adequate quality at the catchment scale, which is normally much finer than the resolution of GCMs, it is necessary to apply regional climate models (RCMs), cf. Dankers et al. (2009), Te Linde et al. (2011), Leander et al. (2008), Varis et al. (2004), and Wood et al. (2004).

Many studies point out that an increase in temperature will intensify the hydrological cycle and intense precipitation will increase, and Kundzewicz and Schellnhuber (2004) conclude that this is a precondition favourable for the development of hydro-climatic extremes and increase of flood hazard. Indeed, intense precipitation has increased worldwide and also in Germany, with higher increases in the western part of Germany (Hattermann et al., 2012). Therefore, there is a growing need for information on climate-change impacts on hydrological extremes and related damages (MunichRe, 2005; Jonkman et al., 2008; Te Linde et al., 2011). Planning in water management refers to the time scale of decades, hence measures implemented now should already take into account possible future climate-change impacts on hydrology (Becker and Grünewald, 2003; Hattermann et al., 2012). 
The insurance sector has an incentive and interest to quantify possible impacts of future climate change on weather extremes in general, and flood losses in particular, in order to be able to adapt insurance offers and to develop new services (GDV, 2010; Berz, 2008; Leipprand et al., 2008). This especially applies to the re-insurance companies, where damages caused by hydro-climatic extremes can accumulate, resulting in huge financial losses (MunichRe, 2005). For example, the financial losses caused by the Elbe and Danube floods in 2002 in Germany were reported to exceed EUR 11.6 billion, of which 1.8 billion were covered by insurance (Thieken et al., 2005), and the losses caused by the Danube and Elbe flood in June 2013 were estimated at approx. EUR 7 billion, of which also 1.8 billion were covered by insurance. Bearing in mind the uncertainty about climate-change impacts on flood losses, the German Insurance Association (GDV) commissioned a study on possible climate-change impacts on the German insurance industry (GDV, 2010). The aim of this study was to generate information on climate change induced trends in storm events (Held et al., 2013; Donat et al., 2011) and flood damages. The main objectives of this latter part were the following:

- to analyze climate-change impacts on flood hazard (frequency, intensity, and seasonality of floods) in large river basins in Germany until 2100,

- to project climate change related flood damages considering the current value of assets,

- to analyze and quantify the sensitivity of results to climate scenario uncertainty,

- to identify information gaps and scientific challenges.

The principal research question addressed in this paper is to estimate what flood damage would occur in individual river reaches of Germany under present conditions, should the river discharge change according to projections for future climate in two time horizons (2041-2070 and 20712100). This question was explicitly posed by stakeholders of the project from the insurance sector, interested solely in determining the pure climate-change impact on flood hazard and related flood damages, thereby neglecting other nonstationarities (change in infrastructure, value of assets etc.). The present study, covering the whole of Germany, quantifies the sensitivity of flood damages to climate variability and change only, and does not estimate the actual future flood damages. In the latter case, also such factors as changes in land use (e.g., riverine settlements), water management (e.g., flood protection), and changes in the value of assets would have to be considered (Tu et al., 2005; Helms et al., 2002).

A panel of experts from the science and insurance sectors (comprising among others Munich RE, Deutsche Rück, Swiss Re, AllianzSE, Nürnberger Beteiligungsgesellschaft, Provinzial Rheinland Versicherung AG and the German Insurance Association GDV) consulted the overall process and

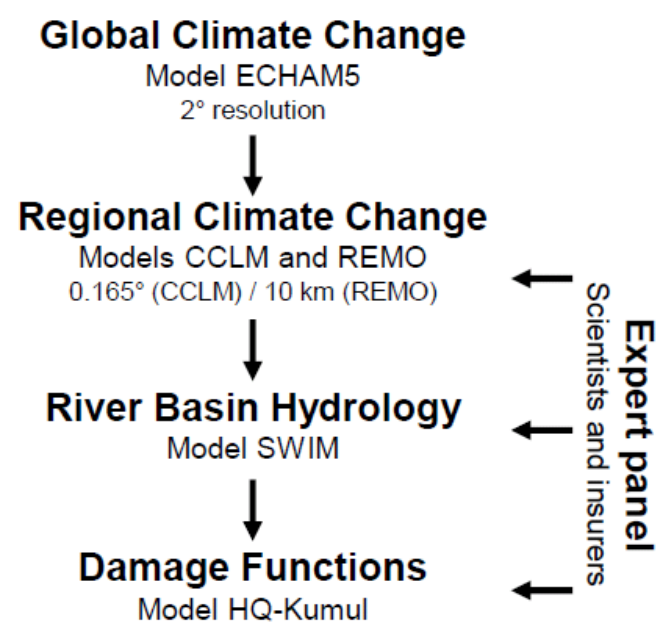

Figure 1. Model system and data and information flow applied in the study.

reviewed the single modelling steps and results on a regular basis (every 2-3 months) and gave recommendations for improvement which were considered by scientists (see Fig. 1). Intensive communication and trans-disciplinary exchange between scientists and insurers proved to be key for finding meaningful solutions e.g., concerning linking of hydrological modelling and damage functions.

The next section briefly describes the overall modelling strategy, the models used and the information flow. A more comprehensive description of the methodology used to produce damage reference information can be found in the Annex. The results of validation exercises and then scenario projections, for hydrology and flood damages, are presented, including a brief discussion of the propagation of climate change uncertainty to flood losses. The study also contains a critical review of the methodology applied.

\section{Material and methods}

\subsection{River basins and related data}

Germany (area of $357021 \mathrm{~km}^{2}$ ) is divided geographically into the northern German lowlands, the central German upland, the southwestern Rhine Valley, the Alpine foreland and the German Alps (see Fig. 2a). From the northwest to the east and southeast, the maritime climate gradually changes into a more continental climate. The country's average annual temperature is about $+9^{\circ} \mathrm{C}$, and the prevailing winds are westerly. Precipitation occurs in all seasons, with substantial regional differences. In the northern German Lowlands, annual rainfall varies between less than 500 (continental) to about $700 \mathrm{~mm}$ (maritime). The upland and mountainous areas receive from about 700 to more than $1500 \mathrm{~mm}$ of precipitation per year, and high altitudes in the Alps more than $2000 \mathrm{~mm}_{\text {year }}{ }^{-1}$ (Statistisches Bundesamt, 2008). 


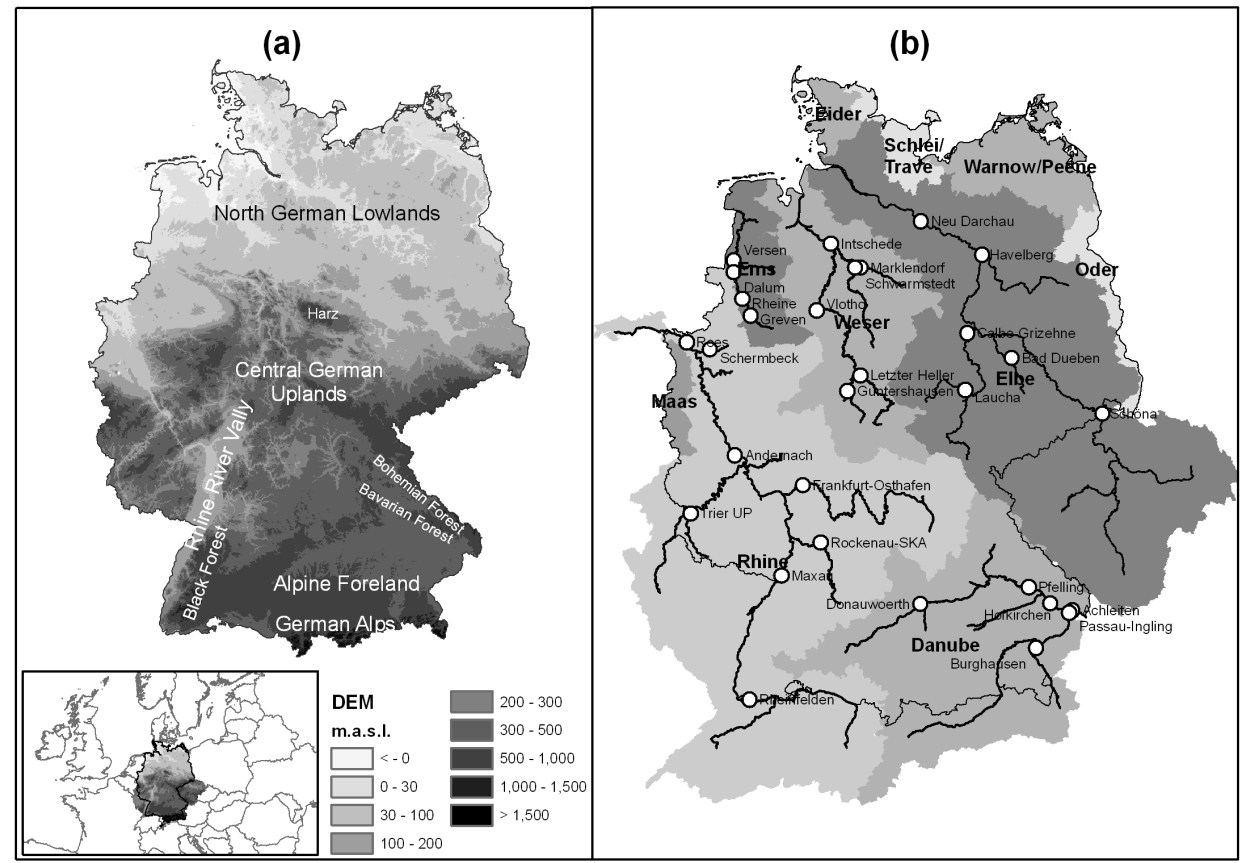

Figure 2. (a) Topography of Germany and (b) the five largest river basins including location of gauges for calibration and validation.

The German territory is comprised of five large river basins (the Elbe, upper Danube, Rhine, Weser and Ems), three medium-scale basins in the coastal area (Eider, Schlei/Trave and Warnow/Peene), and small parts of the Oder and Meuse basins (see Fig. 2b). Of the large river basins, only the Ems and Weser basins lie entirely within the borders of Germany. The Rhine, upper Danube and Elbe are international rivers and their drainage basins have large parts outside Germany.

All spatial information applied in the study (the digital elevation model (DEM), the soil, land use and water table contour maps) is stored in a grid format with $250 \mathrm{~m}$ resolution. The DEM information originates from re-sampling of digital elevation data of the STS-99 Shuttle Radar Topography Mission (SRTM) (Jarvis et al., 2008).

Sub-basin boundaries were provided by the German Federal Environmental Office (UBA), and for areas located outside Germany they were calculated using the DEM.

The land use map was created using the European CORINE (COoRdination of INformation on the Environment) land cover map (Dollinger and Strobl, 1996). The original 44 land use classes were reclassified into 15 classes (Krysanova et al., 2000).

Soil information was taken from the soil map of the Federal Republic of Germany (scale $1: 1000000$ ). The map distinguishes between 72 different soil types. Each soil type has a so called "leading profile" with up to 8 different layers. Alongside the soil map, physical parameters for each layer, such as saturated conductivity, texture classes, porosity, bulk density, humus and organic nitrogen content are provided.

\subsection{The modelling strategy}

The setting of the overall modelling strategy is the result of a longer discussion process between scientists and insurers. This section describes the information flow from climate scenarios to estimates of future flood damages, reflecting the state-of-the-art scientific knowledge, as well as the information demands of the insurers, in terms of spatial and temporal resolution. The information flow within the modelling framework used in this study (Fig. 1) encompasses the regional climate scenario data, the hydrological model which transforms the scenario data into river discharge for individual river sections, and the damage functions to calculate the financial flood losses.

Simulations from the ECHAM5 global circulation model (GCM), cf. Röckner et al. (1999, 2003) were chosen as largescale climate drivers because analysis has shown that the model simulation results agree reasonably well with the observed climate in the target area (Germany) for the reference period 1961-2000.

Different regional climate model (RCM) applications, based on ECHAM5-generated scenarios as drivers, are available for Germany, using dynamic and statistical downscaling. In this study, the available regional climate scenarios generated by the physically based models (CCLM and REMO) were used for impact analysis. In total, seven transient runs from 1961-2100 were applied, of which four were generated by CCLM (corresponding to IPCC SRES scenarios A1B and B1 with two realizations each, cf. Hollweg et al., 2008) and three by REMO (IPCC SRES i.e., Nakićenović and Swart, 
2000, scenarios A1B, A2 and B1 with one realization each, cf. Tomassini and Jacob, 2009).

The climate scenarios were transformed into river flow and flood frequency characteristics using the eco-hydrological model SWIM (Krysanova et al., 1998), which had been validated and applied for the target area (Huang et al., 2010, 2013; Hattermann et al., 2011). In this paper, it was used for investigation of 5473 river reaches of Germany.

The last step of the work flow diagram was to transform the projected river flows into losses using damage functions developed by the German Insurance Association for the zip code areas in Germany (GDV, 2009).

\subsection{The regional climate models}

REMO (Tomassini and Jacob, 2009) and CCLM (Böhm et al., 2006) are physically based regional climate models, which calculate climate variables on a dense grid. REMO used a $10 \mathrm{~km}$ grid for central Europe including Germany, while CCLM used a $0.165^{\circ}(18 \mathrm{~km})$ grid for entirety of Europe. Both models use results of the GCM ECHAM5 (Röckner et al., 2003) as boundary conditions and generate the main weather processes and variables for the region of interest including temperature, cloud dynamics, and precipitation for each grid cell. Theoretically, physically based climate models could be perfect tools to investigate regional climate change as they consider the basic physical relationships of climate dynamics. However, the physical nature of weather and climate processes is very complex. Even if the models are being improved (Wood et al., 2004), cloud physics and the development of precipitation are still difficult to reproduce. The reason why a set of climate projections produced by different regional climate models and driven by different global scenarios have been applied in this study, is in order to reflect the inherent uncertainty of the climate projections.

The spatial distribution of intense precipitation is a prerequisite for interpretation of flood generation as often floods develop in the headwaters and different tributaries can contribute to floods in the main river. Despite the uncertainty in projections of intense precipitation, Seneviratne et al. (2012) show that what used to be a 20 -year return value of annual maximum $24 \mathrm{~h}$ precipitation rates in late 20 th century is projected to be exceeded more frequently in the future. A daily precipitation sum that used to be reached (or exceeded), on average, every 20 years in the reference period is projected to become much more frequent in future. For the Central European region it may re-occur every 9-14 years (depending on time horizon considered and on SRES emissions scenario). A similar pattern can also be seen in the climate scenario realizations used for this study.

\subsection{The hydrological model SWIM}

The ecohydrological model SWIM, used in this study, integrates the relevant processes necessary to investigate the im- pacts of climate change on water resources, such as evapotranspiration, percolation, surface runoff, interflow, groundwater recharge, plant water uptake, vegetation dynamics and river routing (Krysanova et al., 1998; Hattermann et al., 2005). A comprehensive description of the model can be found in Krysanova et al. $(1998,2000)$. The model has been already applied in different hydrological studies in Germany (Hattermann et al., 2004, 2006, 2007, 2008b; Krysanova et al., 2002; Huang et al., 2009, 2010, 2013). Hattermann et al. (2005) calibrated the model for the Elbe basin including quantification of sensitivity and uncertainty, while Huang et al. (2010) calibrated the model for all large river basins in Germany in a climate impact study. Investigation of climate change impacts on floods using the results of different RCMs as climate boundary condition was carried out by Huang et al. (2013) and Hattermann et al. (2011).

SWIM uses a three-level scheme of spatial disaggregation from basin to sub-basins and finally to hydrotopes (sets of elementary units in the sub-basin, with common geographical features like land use, soil type, and average water table depth). Water fluxes, plant growth and nutrient dynamics are calculated for every hydrotope with a daily time step. The outputs from the hydrotopes are aggregated at the sub-basin scale. The lateral fluxes are routed over the river network, considering transmission losses.

The Turc-Ivanov (DVWK, 1996) method is used to estimate potential evapotranspiration. Soil evaporation and plant transpiration are calculated as functions of the leaf area index (LAI) using the approach of Ritchie (1972). Surface runoff is determined using a modification of the soil conservation service (SCS) curve number technique. Infiltration of water into the soil, percolation through the soil layers and groundwater recharge are modelled using a storage routing technique (Arnold, 1990).

Lateral subsurface flow or interflow is calculated simultaneously with percolation using a kinematic storage model. Interflow occurs in a given soil layer if the soil layer below is fully saturated. Flow routing in the river network is calculated using the Muskingum flow routing method (Maidment, 1993). Slope, depth and width of river reaches are calculated using a digital elevation model of $100 \mathrm{~m}$ resolution. The equations for groundwater flow and groundwater table depth were derived from Smedema and Rycroft (1983).

In total, the model set-up for the task reported in this paper consists of 5473 sub-basins and 124671 hydrotopes (thereof 3766 sub-basins and 63926 hydrotopes in Germany).

\subsection{The damage functions $D_{(T)}$ and the flood loss model HQ Kumul of the GDV}

There exist many different methodologies to derive flood losses (Merz and Thieken, 2009; Apel et al., 2009a), typically in the suite: discharge (stage) - damage, or discharge - return period - damage, developed for a range of scales from local to national or continental. However, the issue of 
establishing damage functions remains a difficult one. Merz et al. (2013) examined stage-damage functions linking the damage (relative or absolute) for private households in Germany to the inundation depth. Even if one typically ignores many factors influencing flood damage, Merz et al. (2013) considered hydrological and hydraulic aspects, early warning and emergency measures undertaken, state of precaution of the household, building characteristics and socioeconomic status of the household.

Cammerer et al. (2013) examined adaptability and transferability of stage-damage functions for the estimation of direct flood damage to buildings. Despite the vast uncertainties, transferability is tacitly (and incorrectly) taken for granted without further validation, mainly due to the lack of real damage data. Cammerer et al. (2013) found that flood-loss functions derived from related and similar regions estimate the observed damage quite well indeed, while careful thoughts are needed when transferring loss functions to other geographical regions.

Meyer et al. (2013) undertook a review of cost assessment approaches for natural hazards, including floods. Different cost types were considered: direct tangible damages, losses due to business interruption, indirect damages, intangible effects, and costs of risk mitigation. Meyer et al. (2013) showed that cost assessment is often incomplete and biased; direct costs receive principal attention, while intangible and indirect effects are ignored. Cost assessment is bound with huge uncertainties due to insufficient or highly aggregated data sources, along with a lack of knowledge about the processes leading to damage.

Dumas et al. (2013) examined methodology to investigate the causal chain from global climate change to local flood losses in France, finding that a very large uncertainty arises from the climate downscaling technique. According to $\mathrm{Du}-$ mas et al. (2013), there are doubts as to the feasibility of estimating future flood losses at local scale.

A regional study devoted to the impact of climate change on flood damages on the pan-European scale, by Feyen et al. (2008), arrived at averaged expected annual damages at the EU and country level. It was assumed that the flood protection level depends on the country's GDP (protection up to 100,75 , and 50-year flood for countries with GDP above $110 \%$; in the range from 55 to $110 \%$; and below $55 \%$ of the average EU 27 GDP level, respectively). It was also assumed that no adaptation to increasing flood levels and no growth in exposed values was made. Under these assumptions, the expected annual damage (of EUR 6.5 billion at present) was projected to nearly treble, to EUR 18 billion in 2071-2100 under SRES A2 scenario. Out of 25 EU countries with nonzero flood damages in the control period, increase (up to $80 \%$ ) is projected in 20 and decrease (even by $85 \%$ ) is projected in five countries.

The damage functions used in the present paper have been provided by the German Insurance Association (GDV). They link potential flood damage with return period of river dis- charge for post zip code of the area for present conditions. Below some threshold return period there is no damage (cf. Fig. 3). Figure 3 illustrates how the concept of the damage function is used. Such functions exist for the whole country, ordered by zip code numbers, but they are not in the public domain, as they are of considerable commercial value. Willems (2010) examined the relations between five-digit post zip code numbers and individual river reaches in Germany.

The damage functions used in this study are an integral part of the flood loss model HQ Kumul (Burghoff, 2008; GDV, 2009), a physical-probabilistic model for assessment of flood damages at residential houses and buildings of small enterprises including interiors. Even if HQ Kumul is not in public domain, it is available to members of the German Insurance Association GDV, so that it is being used by insurance companies in Germany in their daily work to estimate potential flood losses. The approach combines information about historical flood events, flood frequency statistics, and related damages, with a zoning system (ZÜRS GEO, see www.zuers-public.de), indicating areas at risk for specific flood return periods under current climate and runoff conditions.

The approach of the GDV determines possible flood damage $D_{(T)}$ considering inundation areas for flood with certain return period and value of the goods (buildings and small enterprises) located in the affected areas. The damage function has a form of a table of damages for each postcode area in Germany including zip code, flood return period $T$, and related losses. In order to link these damage functions to the river network, a representative damage function has been assigned to each river reach (Fig. 3, bottom), accounting for the distance of the neighbouring post code areas to the river and size of the area affected by the specific river reach (Willems, 2010).

The HQ Kumul approach is designed to indicate flood risk areas under current conditions using observed discharge as input. Changes in runoff conditions and climate cannot be considered as no dynamic rainfall-runoff model is included. This is why the damage information for the period 19612000 derived from HQ Kumul and validated against data collected by GDV can serve in this study only as a reference for comparison with the damage results generated by SWIM (with observed climate data or RCM-generated climate input) for the same period. For a future scenario horizon, no observations of runoff exist and thus they are simulated by the SWIM model driven by RCM projections and linked to the present damage functions of HQ Kumul to calculate losses under climate change conditions, considering the current value of assets. For more information about HQ Kumul, see the Appendix. 

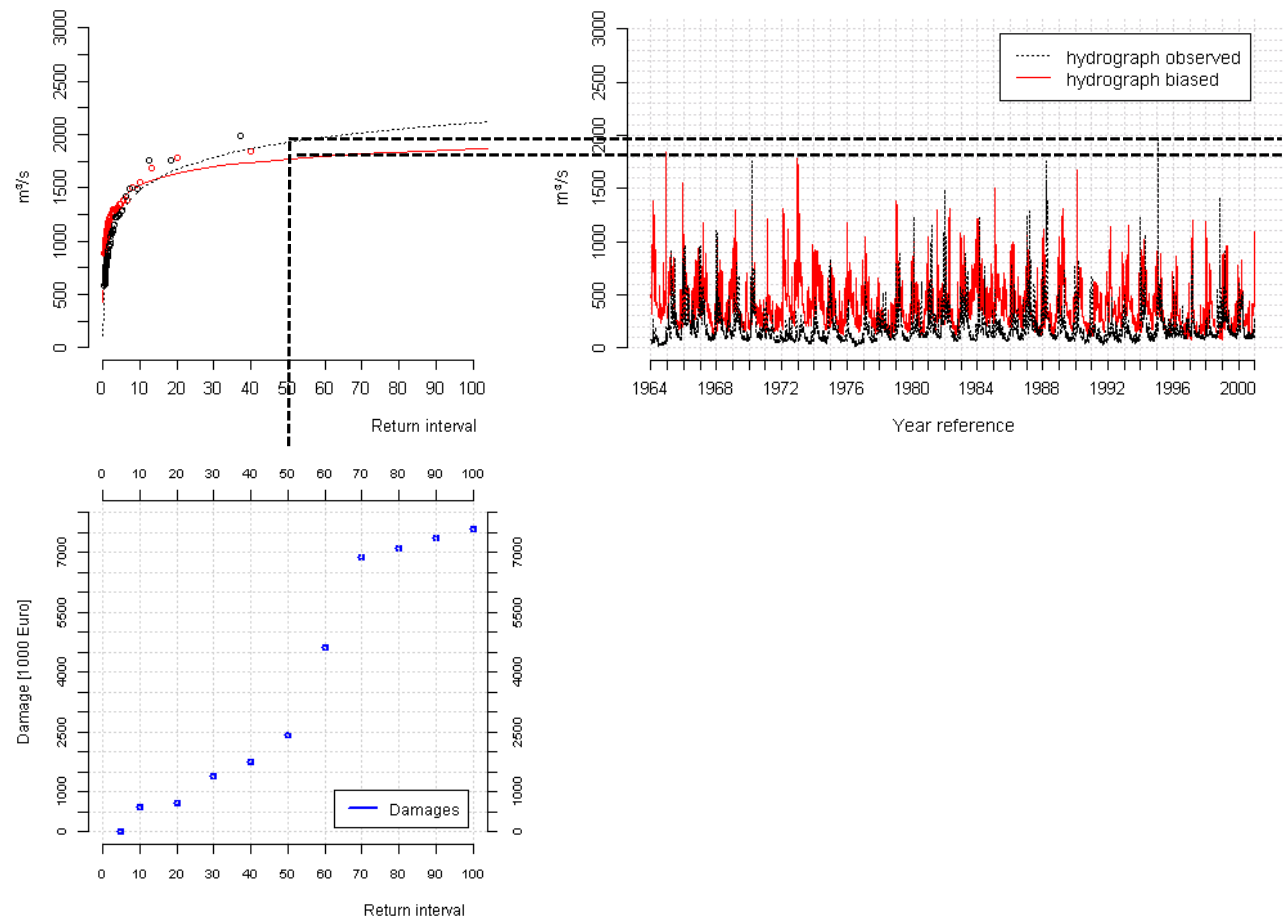

Figure 3. From river discharge (top right) via extreme value statistics (top left) to flood damages (bottom).

\subsection{Linking flood statistics to damage functions}

One of the most critical steps in deriving flood losses is to combine hydrological information with economic information, via damage functions. GDV provided data on flood losses for various spatial units and for various return periods. The idea is therefore to make use of appropriate extreme value statistics and to derive a value of discharge corresponding to a particular recurrence interval $T$ for the reference period 1961-2000, using the output of the hydrological model driven by the RCM simulations. This will allow the analyst to calculate $T$ as input to the damage function $D_{(T)}$.

When investigating extremes, events located in the tails of the distribution are in the focus of interest (Coles et al., 2001). In the statistics of extreme events, one takes advantage of a theorem which describes the statistical behaviour of extreme events (the so called extremal types theorem (ETT), c.f. Coles et al., 2001), asymptotically for large samples. In other words: when generating many random distributions which are not necessarily normally distributed, the mean of this set is found to be approximately normally distributed. When selecting the extreme values of the same sets of data, they asymptotically approach one of three other types of distributions, which can be written in a single expression as a family of generalized extreme value (GEV) distributions. Either maximum values of discharge (e.g., annual maximum, AM) or peaks over a threshold (POT) can be analyzed. For the POT approach, a threshold $(u)$ is first determined, and events $(x)$ above that threshold are fitted to the generalized
Pareto distribution (GPD) (Coles et al., 2001):

$F_{q}(x) \simeq G(x ; \tilde{\sigma}, \zeta, u)=1-\sqrt[\zeta]{1+\frac{\zeta(x-u)}{\tilde{\sigma}}}$,

asymptotically for large $u$ with $x-u>0,1+\frac{\zeta(x-u)}{\tilde{\sigma}}>0$ and $\tilde{\sigma}=\sigma+\zeta(x-u)$, where $\sigma$ and $\zeta$ denote scale and shape parameters. Summarizing, the GPD gives the probability $P$ of a random variable exceeding a high flow value given that it already exceeds a high threshold $u$ in $\mathrm{m}^{3} \mathrm{~s}^{-1}$, whereby the value of $u$ has to be carefully determined (Coles et al., 2001). By setting the cumulative distribution function (cdf, Eq. 1) equal to the probability of interest, and then solving for $u$, one gets the corresponding return level (flow) $q$ in $\mathrm{m}^{3} \mathrm{~s}^{-1}$. The resulting $T$ year return level is defined as follows:

$q=u+\frac{\tilde{\sigma} \cdot\left(\left(T \cdot n_{u} \cdot \operatorname{Pr}(x>u)\right)^{\zeta}-1\right)}{\zeta}$,

with $n_{u}$ the number of (flow) observations per year (on average 365.25 as we operate with daily data) and $\operatorname{Pr}(x>u)$ the number of events larger than $u$. Equation (2) can be further developed to get the return period $T$ in years of every return level $q$ :

$T=\frac{\sqrt[\zeta]{\frac{q-u}{\tilde{\sigma}} \cdot \zeta+1}}{n_{u} \cdot \operatorname{Pr}(x>u)}$.

\subsection{Bias correction}

Many studies (e.g., Piani et al., 2010; Dankers et al., 2009; Dankers and Feyen, 2009; Huang et al., 2013) discuss how 
to apply climate scenario data in impact studies and how to overcome the inherent inaccuracy (bias) of the simulated climate data. It is often stated that climate data simulated by GCMs and RCMs have to be corrected before being applied in impact studies (Piani et al., 2010). However, there are also disadvantages of bias correction, e.g., inability to detect the causes of the observed bias leading to errors in simulation. Moreover, bias correction methodologies suggested in literature are not reliable when correcting precipitation extremes, as these events by definition occur very rarely, hence the statistical support for any correction is low because of the very small sample size. Also, measurements of extreme events are often uncertain because of the low density of monitoring stations and existence of large measurement errors. The projections of extreme events are more uncertain than projections of mean conditions. Besides, a recent study by Huang et al. (2014) has shown that bias correction neither improves reliability nor reduces uncertainty of flood projections. In addition, applying the "best" possible bias correction method for one variable will not give "perfect" results in terms of another variable and a bias will still occur. This bias will add to the measurement and interpolation errors.

The damages in HQ Kumul are solely a function of return periods $T$ (of the reference period 1961-2000), while each $T$ can also be associated with a particular value of discharge $q$. The bias in discharge $q$ is caused by the bias in RCM climate input which differs from the observed climate. It is assumed that the bias correction for the reference period is valid for future periods. In practice, one has to derive the discharge cdf under RCM climate for a river reach and the reference period 1961-2000 (Fig. 3 top left) and apply this function to a (scenario) discharge time series of the same river reach (Fig. 3 top right) and using the same RCM climate forcing. This has to be done for each of the seven scenario realizations separately. Doing so, the correction is implicitly applied to a time series of discharges $q$, i.e., correcting the discharge associated with return periods $T$ of the RCM discharge cdf's in order to match the reference discharge cdf's. A table giving damages $D_{(T)}$ for specific values of return interval $T$ (Fig. 3 bottom) is then used to calculate flood loss for all values of $q$ in future (2011-2100). This is done for every single event and each of the 3766 sub-basins modelled in Germany.

The bias correction in this paper refers to rectifying the errors identified in the link between the discharge and the return period in the reference period. In this way, the bias correction is shifted to the end of the model chain. The advantage of this shift of bias correction is that one does not have to do corrections for every single modelling step (climate modelling, hydrological modelling, damage modelling). Nevertheless, comparison with hydrological simulations based on observed climate as input is still useful to estimate the performance of the hydrological model for extreme conditions, and comparison of simulated and observed climate for the reference period is necessary to understand the inherent uncertainties in climate input variables.
The procedure can be summarized as follows.

1. Simulate discharge for the reference (1961-2000) and scenario period (2001-2100) for each of the 3766 river sections with SWIM (driven by the respective RCM).

2. Define scale and shape parameters of GPD by fitting the return intervals of discharge above threshold $u$ (here the 99th percentile of daily discharge) for the reference period and for each river section.

3. Calculate $T$ for the daily discharge in the scenario period for each day and each river section using the cdf with GPD parameters derived in the reference period.

4. Calculate the river section specific damages $D_{(T)}$ for each day of the scenario period.

This way it is assumed that every time when a runoff occurs in a specific river reach having the discharge of e.g. the 50year flood of the reference period it will cause the related damages.

\section{Results and discussion}

\subsection{Validation of discharge and damage for the reference period}

\subsubsection{Hydrology}

Figure 4 (left) shows the observed and simulated daily river discharge from 1981-1990 (for visualization purposes - only 10 years). Figure 4 (right) displays the flood statistics (GPD) calculated using data from the period 1951-2000 and for the observed and simulated floods over a threshold $u$ of the 99th percentile of daily flow. The examples were selected in such a way that the basins represent the main regions in Germany.

Figure 4 illustrates that the SWIM model is generally able to reproduce both the flow dynamics and the extremes in river basins with quite different flow regimes, ranging from lowland areas under maritime and continental climate to subalpine areas. The shape of the GPDs calculated with observed flood events agrees with the ones of the simulated GPDs (right part of the figure).

In a regional model set-up, the simulation generally gives a better reproduction of river discharge from entire large basins and larger tributaries than from the smaller and very small ones. For a better reproduction of the very small tributaries and creeks, site-specific local data should be applied in the model set-up, especially if river flow is affected by human regulation. This is normally not feasible in a regional model application. However, the results in Huang et al. (2010, 2012) using the same model set-up as in this study show that SWIM is also generally able to simulate the behavior of smaller tributaries with satisfactory accuracy. 

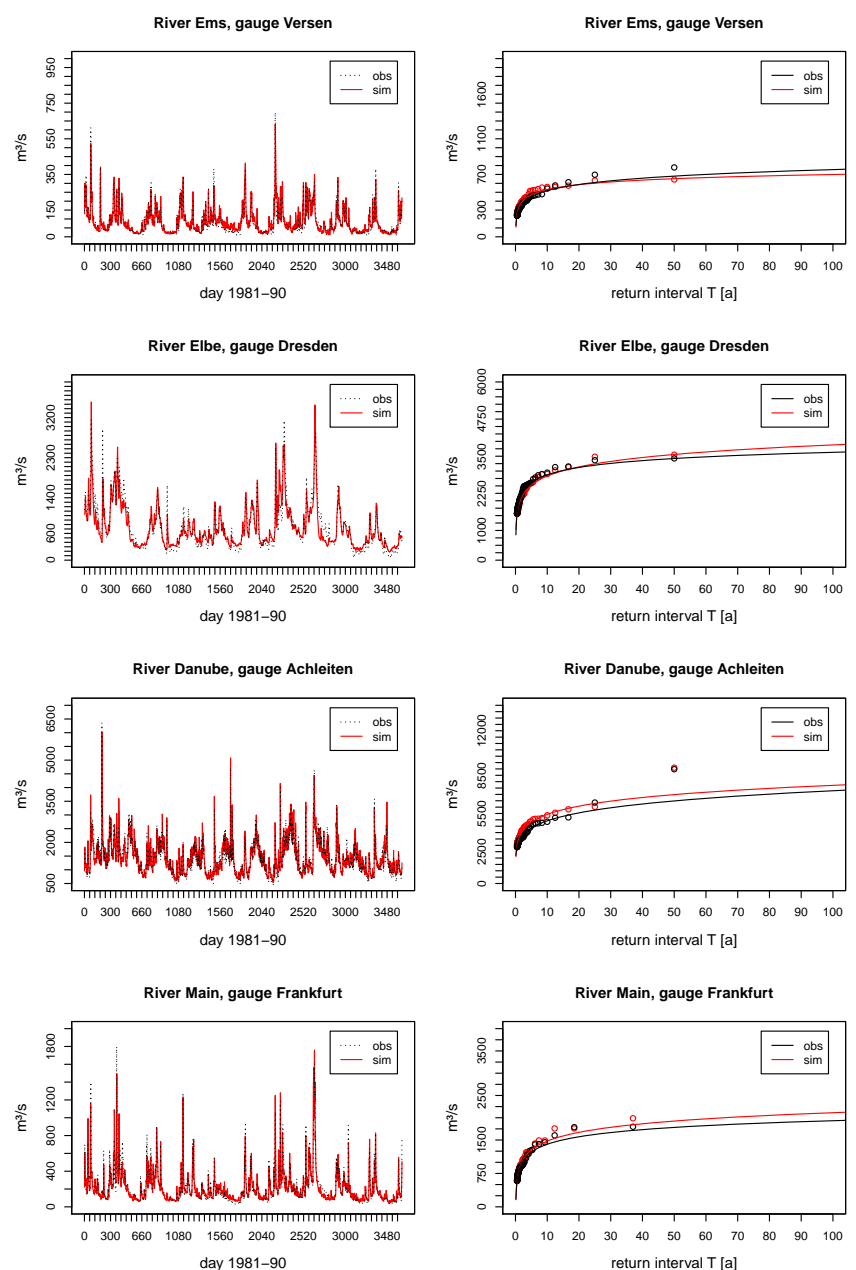

Figure 4. Daily river flow, observed and simulated with observed climate as input for the rivers Ems, Elbe, Danube and Main (for the location of the gauges, cf. Fig. 2). Left: daily runoff 198190. Right: extreme value functions (GPD) calculated for the period 1951-2000.

Figure 5 shows the comparison of simulated flood statistics for the reference period 1961-2000 (the RCM time series starts in 1961) when calculated by SWIM (i) with observed climate as input and (ii) with climate input simulated by CCLM and REMO (CCLM with two control runs, REMO with one). Using the simulated climate as a boundary condition for the hydrological model produces a bias when compared to the results simulated with the observed climate as input. This bias for the reference period is sometimes stronger (Elbe basin) and usually positive with CCLM climate as input, while negative with REMO climate as input. Most comparisons give results similar to those for the rivers Ems and Danube, while some show a strong overshooting or undershooting of the GPD with simulated climate as input, as in the case of the rivers Elbe and Main.

Mathematically, this problem is taken into account by using only the return interval $T$ as a link to the damage function
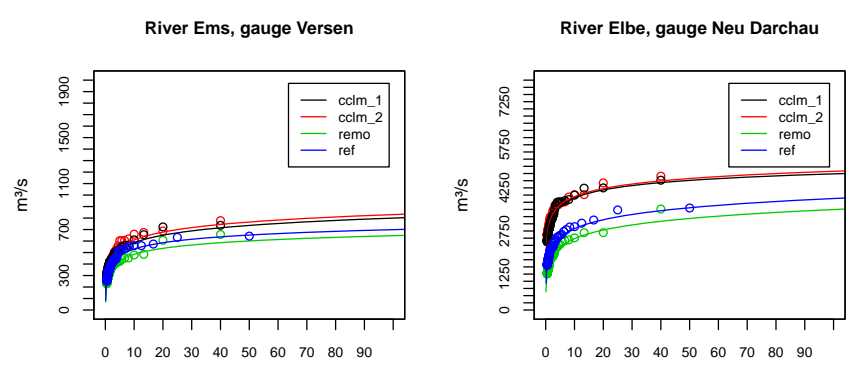

return interval $\mathrm{T}[\mathrm{a}]$
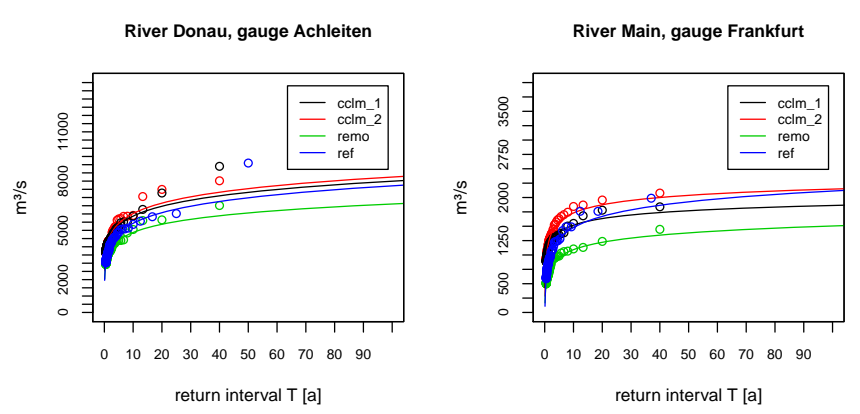

Figure 5. Extreme value statistics (GPD) with observed and simulated climate as input for the hydrological model, for the rivers Ems, Elbe, Danube and Main (for the location of the gauges see Fig. 2) and for the period 1961-2000.

(see Fig. 3 and Eq. 3). Nevertheless, good agreement of the results would render the outcome more trustworthy, as rated by stakeholders.

\subsubsection{Flood damages - reference period}

The flood damages simulated by SWIM linked to the damage functions for the reference period 1961-2000 are compared against GDV loss records derived via HQ Kumul. The first comparison is for specific river reaches where gauges are located. Extreme value statistics were applied for the observed and simulated runoff (GPD) with observed climate as input and used to calculate the flood damages using Eq. (3) and the damage functions of the GDV. Figure 6 shows a typical example in terms of the annual flood damages for the Rhine River reach at Cologne in 1961-2000. Also shown is the long-term average annual damage. Especially the second half of the period shows a very good agreement. An event in 1970 is underestimated by SWIM and the timing of the double-peak January 1983 event is offset. However, the longterm average damages are very similar (see also Table 1).

Figure 7 shows the result for the whole of Germany as simulated by SWIM with the observed climate as input, and as calculated by the hydro-statistical model of the GDV (HQ Kumul) for the same period. The differences for the entire basins are in total higher than for the comparison of specific river reaches. One reason is that the heterogeneity of the results increases with the number of river basins, when dif- 


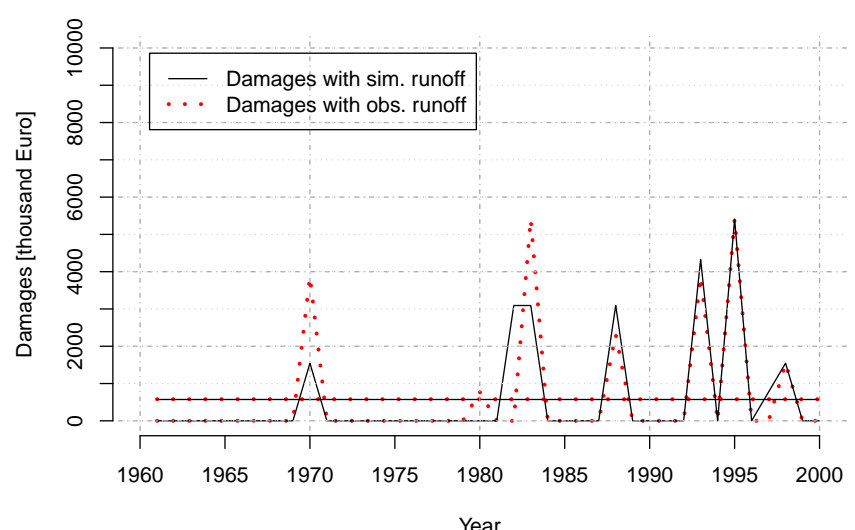

Figure 6. Average annual damages in thousand EUR in the approximately $25 \mathrm{~km}$ long river reach of the Rhine at Cologne calculated using the river reach specific damage function with (i) SWIMmodelled discharge and (ii) observed discharge at gauge Cologne. The long-term mean is also displayed (see also Table 1).

Table 1. Average long-term annual damages in the main German river basins and aggregated for Germany (five large basins) as simulated by SWIM and by HQ Kumul in million EUR.

\begin{tabular}{lcccccc}
\hline & Rhine & Elbe & Danube & Weser & Ems & Germany \\
\hline HQ Kumul & 170 & 92 & 59 & 87 & 39 & 465 \\
SWIM & 151 & 111 & 72 & 98 & 55 & 488 \\
\hline
\end{tabular}

ferences in individual basins contribute to the entire picture. The second reason is that Fig. 7 shows the comparison of two model results having different modelling concepts. The damage functions (i.e., the return period - damage relation) used in both models are the same, but the SWIM model applies a physically based simulation of flood generation and HQ Kumul uses a statistical methodology. The loss event in 1965, for example, is significantly higher when using HQ Kumul (an overestimation is also found when comparing with the observed data). However, the long-term average of simulated flood damages via both models closely agree, being about EUR 500 million per year (see Table 2). Figure 7 also shows that the linear trend for both models is comparable (meaning that there is already a climate induced trend in damage data).

Table 1 lists the flood losses for the period 1961-2000 for the five largest river basins in Germany, as simulated by SWIM in combination with the damage functions and by HQ Kumul. Again, the values are in good agreement. Only the smallest river basin, the Ems, shows larger differences. On the whole, SWIM tends to slightly overestimate the flood damages as compared to HQ Kumul, by approximately $5 \%$ in total. It is worth mentioning that these results were achieved without further bias correction, i.e., without adjusting the damages simulated by combination of SWIM and damage functions.

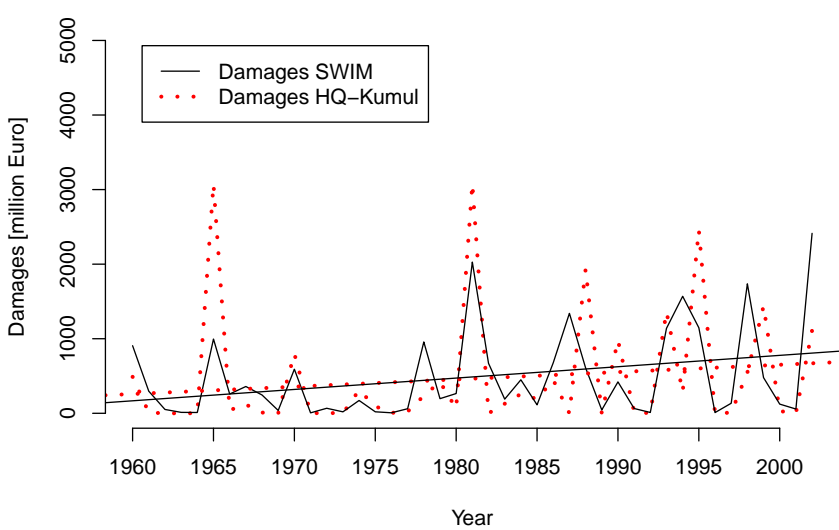

Figure 7. Average annual damages in the main five German river basins as simulated by SWIM and given by the model of the GDV (HQ Kumul) in million EUR. Also included is the long-term linear trend.

Table 2. Return period of a former 50-year flood (for the reference period 1961-2000) under scenario conditions, averaged for all river reaches in Germany.

\begin{tabular}{ccccc}
\hline RCM & $\begin{array}{c}\text { scenario } \\
\text { realization }\end{array}$ & $\begin{array}{c}\text { period } \\
\text { 2011-2040 }\end{array}$ & $\begin{array}{c}\text { period } \\
\text { 2041-2070 }\end{array}$ & $\begin{array}{c}\text { period } \\
\text { 2071-2100 }\end{array}$ \\
\hline CCLM & A1B_1 & 57 & 44 & 19 \\
CCLM & A1B_2 & 21 & 29 & 37 \\
CCLM & B1_1 & 37 & 31 & 65 \\
CCLM & B1_2 & 64 & 23 & 25 \\
REMO & A1B & 38 & 25 & 17 \\
REMO & A2 & 41 & 30 & 22 \\
REMO & B1 & 17 & 23 & 23 \\
\hline
\end{tabular}

\subsection{Projections for scenario conditions}

\subsubsection{Flood hazard under scenario conditions}

Generally, flood hazard increases under scenario conditions in most of the seven scenario runs. Table 2 summarizes the results for all scenario realizations and for three 30 -year horizons 2011-2040, 2041-2070 and 2071-2100. The values indicate the future reccurrence interval of a discharge corresponding to a 50-year flood (in the reference period 19612000) averaged for all river reaches in Germany. Except for the CCLM B1_1 run, all realizations indicate a considerable decrease of the return interval until the end of this century, with the REMO A1b scenario having such an event, on average, every 17 years in the last scenario period, and CCLM A1B_1 scenario - every 19 years.

While Table 2 gives values integrated for the three future horizons and the whole of Germany, Fig. 8 illustrates how the 30-year flood calculated for a 30-year moving window changes at gauge Neu Darchau on the Elbe and under REMO climate scenario projections from 1981 to 2100 in compari- 

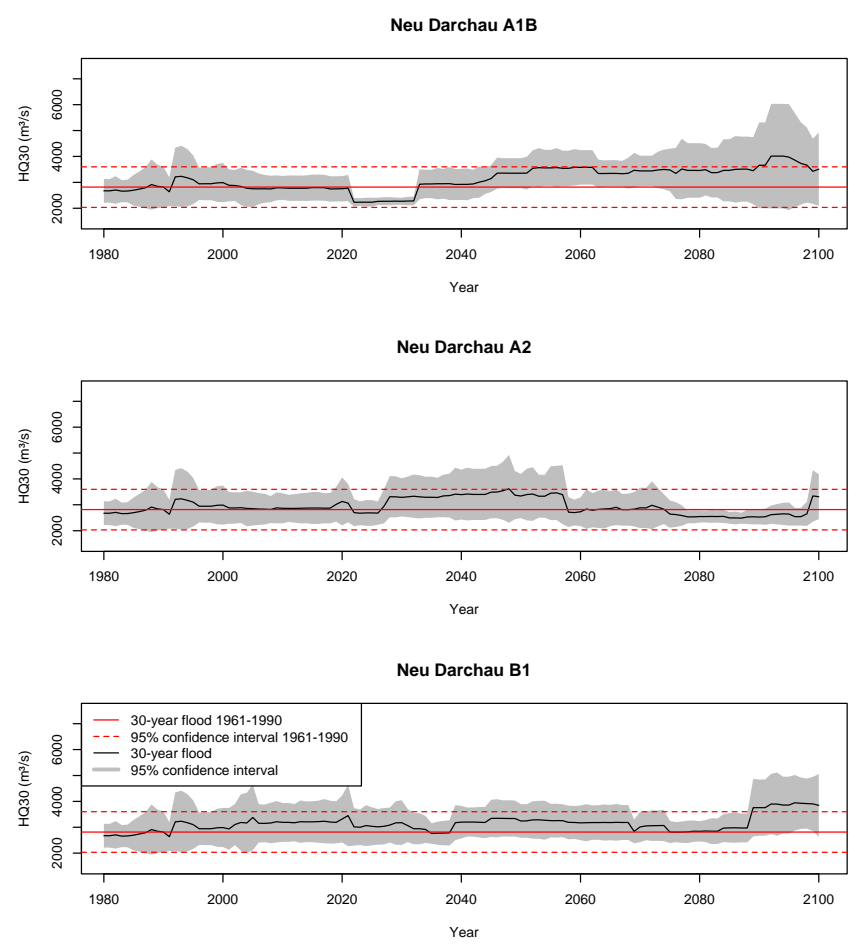

Figure 8. Changes of the 30-year flood calculated for a 30-year moving window at gauge Neu Darchau on the Elbe and under REMO climate scenario projections in 1981-2100 in comparison to the average volume during the period 1961-1990 (in red).

son to the 30-year peak discharge during the period 19611990 (in red) by fitting the GDP for POT events. Shown is also the 95 confidence level. Especially scenarios A1B and B1 show a relatively strong flood increase until the end of this century. The variability of changes in 30-year flood over time also illustrates the non-steady nature of trends, under strong inter-annual variability. Nevertheless, a discharge exceeded, on average, once in 30 years in the control period is projected to occur more frequently in the future (leading subsequently more frequently to the respective damage).

\subsubsection{Flood damages under scenario conditions}

Following the increase in flood hazards described in the previous section, scenario results illustrate that flood damages can increase strongly under climate change (considering the current value of assets, exposure, and vulnerability), although inherent uncertainty induced by the climate projections is large. Table 3 summarizes the damages for the different climate models, scenarios, realizations and scenario periods. Figure 9 shows two possible trends for annual flood damages until 2100 as calculated by SWIM linked to the damage functions with two realizations of the scenario A1B, simulated with the RCM CCLM as input. Both project an increase in flood damages. The first realization has a more gradual increase, and the second one shows a few larger
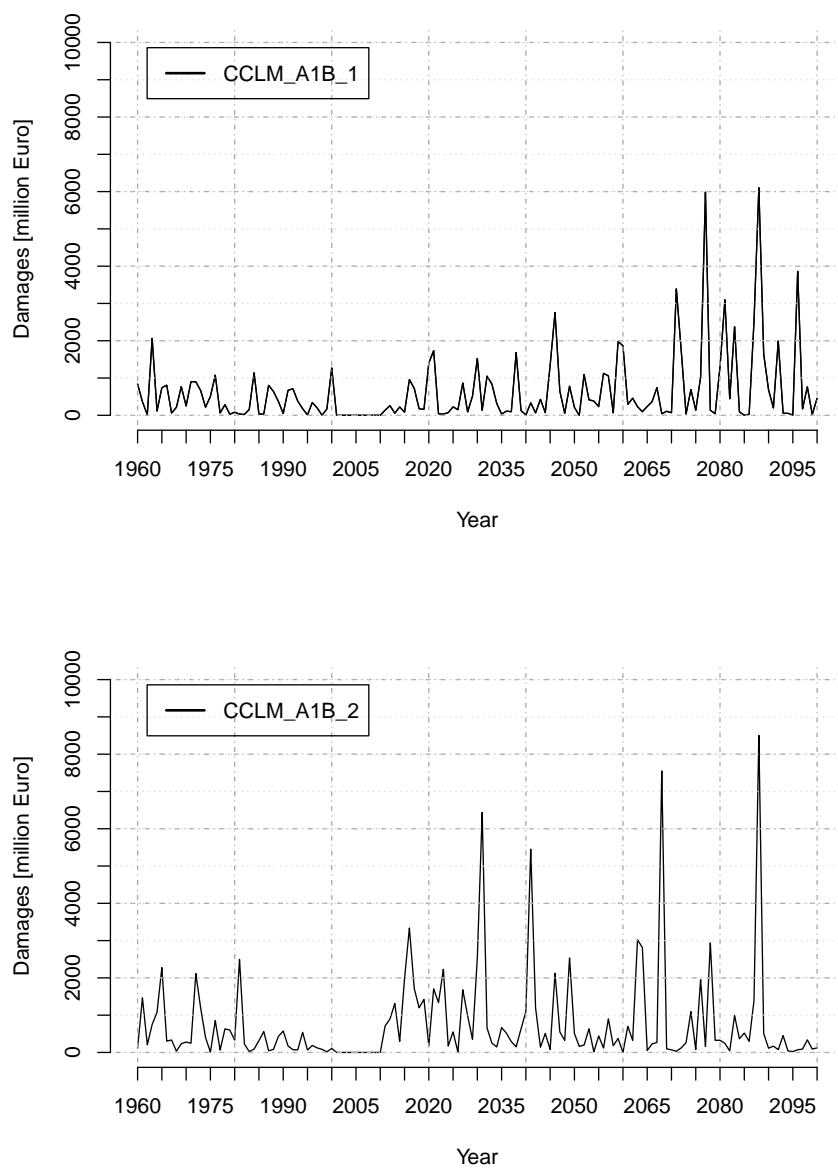

Figure 9. Annual damages in Germany (five largest river basins) as simulated by SWIM in million EUR. Top: scenario CCLM-A1B-1. Bottom: scenario CCLM-A1B-2.

events appearing already in the first scenario period (20112040). In the last scenario period (2071-2100), the A1B_1 run has, on average, flood damages three times higher than in the reference period (1961-2000), while A1B_2 shows that already in the first scenario period the annual damages nearly doubled. The differences of two realizations of one scenario (A1B) modeled by the same regional climate model (CCLM) illustrate the possible heterogeneity of the results within one scenario.

Figure 10 gives the change in flood losses as simulated by SWIM for the German part of the Rhine basin with CCLM and REMO climate data (scenario A1B) as input. Both simulations show a gradual increase in damages with REMO climate resulting in higher damages in total, as it also holds for Germany (see Table 3), where the third period of the REMO A1B scenario has the highest annual damages of all scenarios. The relative increase of damages under scenario conditions reported here is within the range of results published by Te Linde et al. (2011) for the same basin, but considering also land use changes, and published by Feyen et al. (2008) for the European scale. 
Table 3. Average flood damages in Germany per year, for the reference period and scenario horizons (in million EUR).

\begin{tabular}{lcccc}
\hline Scenario/Realization & $1961-2000$ & 2011-2040 & 2041-2070 & 2071-2100 \\
\hline CCLM A1B-1 & 433 & 461 & 585 & 1301 \\
CCLM A1B-2 & 492 & 1183 & 1052 & 725 \\
CCLM B1-1 & 433 & 815 & 878 & 388 \\
CCLM B1-2 & 492 & 668 & 1091 & 1276 \\
\hline REMO A1B & 468 & 672 & 1003 & 1509 \\
REMO A2 & 468 & 748 & 668 & 891 \\
REMO B1 & 468 & 1436 & 929 & 860 \\
\hline Average & 465 & 855 & 887 & 993 \\
\hline
\end{tabular}
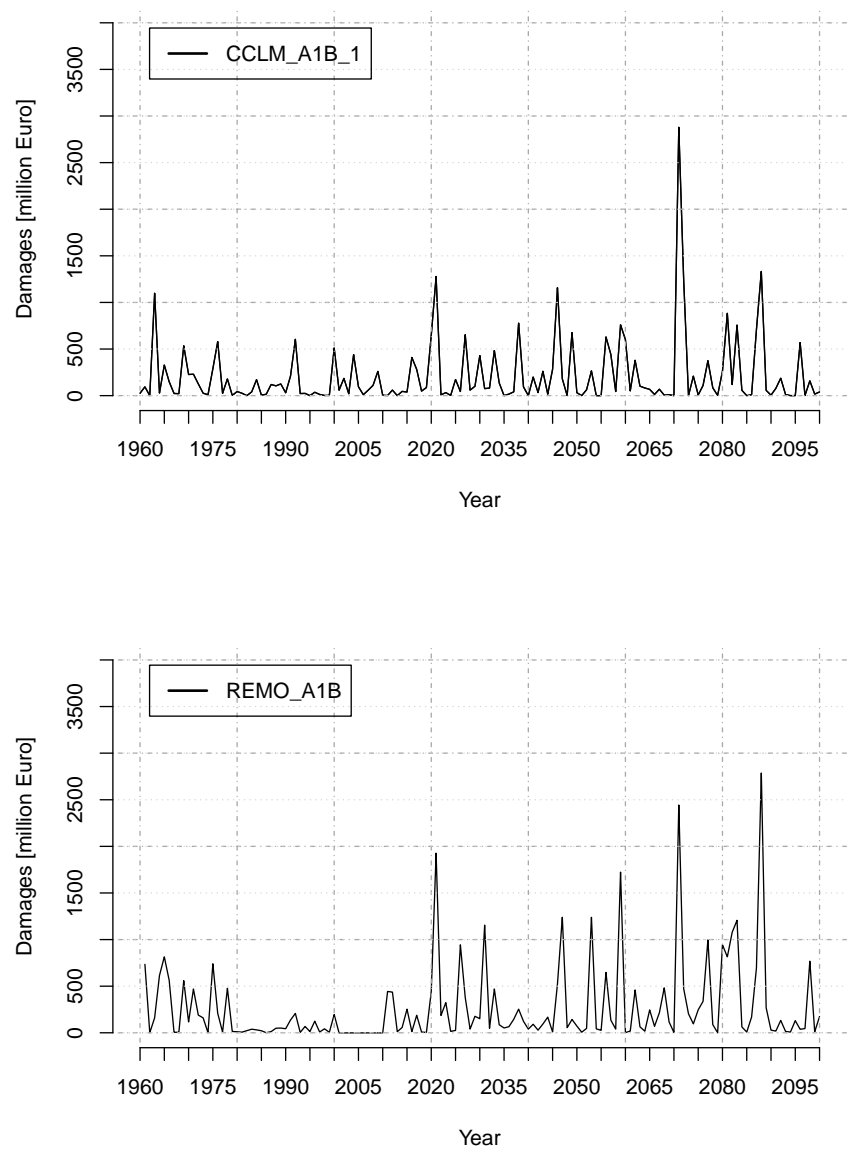

Figure 10. Annual damages in the German part of the Rhine basin as simulated by SWIM in million EUR. Top: scenario CCLM-A1B1. Bottom: scenario REMO-A1B.

The results are summarized for the whole of Germany in Table 3. The total annual flood damages in Germany sum up to nearly EUR 500 million per year for the reference period 1961-2000 and, on average, double (for REMO A1B even treble) until the end of the scenario period.

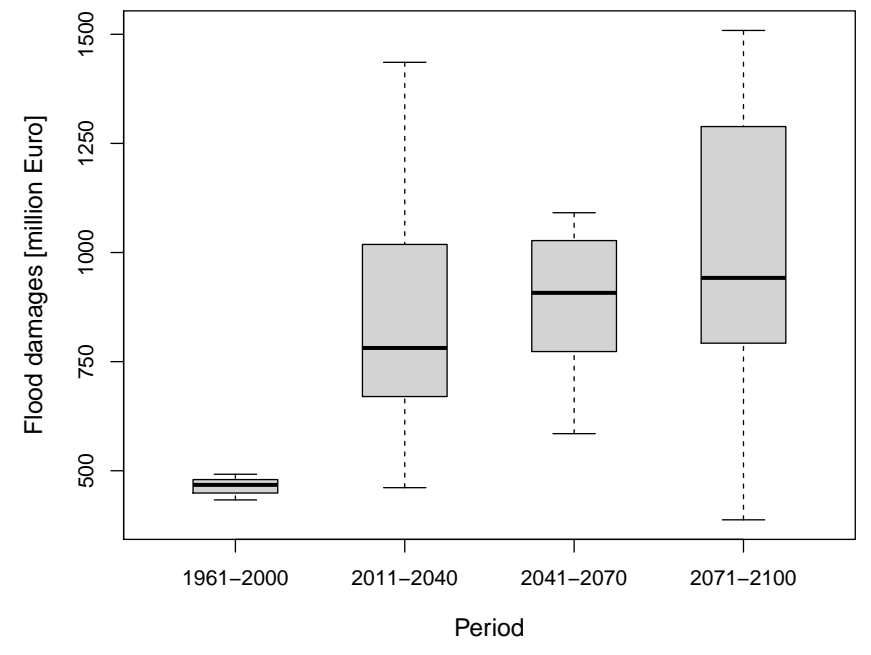

Figure 11. Box plot of the average annual losses per year for all scenarios and time periods in million EUR per year.

Figure 11 summarizes the results for all scenarios, realizations and periods in the form of box plots, indicating the range of uncertainty.

Of interest are the possible reasons for the inherent uncertainty of trends. As shown in Table 3, losses increase under scenario conditions, with the largest average losses occurring for most realizations at the end of the scenario period (20712100). However, even the first scenario period gives a steep increase in damages averaged over all scenarios and realizations, although individual scenarios (CCLM A1B-1 and B12 and REMO A1B) show a more moderate increase (Fig. 11). The underlying reasons can be: (i) the global boundary condition; the ECHAM5 scenarios show a decrease in temperature in the 1990s and a steep increase starting in the early 21 th century, and this pattern is reproduced by the regional models for the study area (see Fig. 3), (ii) the non-linearity of the damage functions, where small increases in flow (if high flows increase then peaks over threshold become more common and their return intervals $T$ decrease) can result in large increases in flood damages and (iii) the inherent uncertainty of the climate processes as such, where only additional 
realizations could help in determination of robust ranges of damage trends, indicating outliers.

It has to be mentioned that the low variability of losses between different simulations in the reference period is the result of the bias correction described in Fig. 3 making the outcome of different climate scenarios and calculated with different RCMs comparable with observed losses.

Figure 12 finally shows four maps aggregating the results of the seven scenario realizations for 3766 river reaches in Germany in terms of flood hazard (upper part) and related damages (lower part) for the periods 2011-2040 and 20412070. The trends in flood hazard are mostly positive for the headwater areas in the mountainous parts of the basins and often along the main rivers, as for the upper parts of the Elbe and Danube rivers. The tributaries from the lowlands often show a decreasing trend, visible e.g., in the northern lowlands of the Elbe basin and in tributaries having their origin in the Rhine Valley (southwest Germany). A second effect is that the western, windward or low parts of the mountains generate relatively more floods and therefore also damages. The reason for the latter effect is that under scenario conditions, more westerly wind situations occur, a pattern already detectable in the observed data for the last five decades (Petrow and Merz, 2009; Hattermann et al., 2012). The trends in flood related damages generally show the same regional pattern with increases in damages where also flood hazard increases.

\subsection{Critical discussion of the methodology applied}

The comparison of the simulated damages against the reference data presented in Table 3 shows that the methodology described and applied here is a useful tool to meaningfully estimate flood damages, under strong uncertainty in data input (e.g., climate) and in model parameters and structure. One conclusion is that the proposed methodology is well suited for large-scale investigations. Nevertheless, also the disadvantages of the methodology should be discussed: considered as driver for changes in flood related damages is only climate, while other sources of uncertainty, which could possibly induce even higher uncertainty than climate projections, e.g., changes in land use, water management and flood defenses as well as changes in flood protection standards and in damage potential (value of assets) are not taken into account. The population exposed to floods (assuming constant hazard), for example, tends to grow, both in absolute terms (thousands of people per year) and in percentage of total population (Kundzewicz et al., 2014).

Another important point which has to be checked in advance when applying the methodology described in this study is that the climate input should create a bias only, not a completely different system behaviour, where the dominating flood generating processes may change. This can be tested by comparing the shape of the hydrographs and frequency distributions (see for example Fig. 3). If a bias is present, the shapes of the hydrographs and frequency distri- butions are only shifted, but not necessarily different. Also, the methodology was developed for regional or large scale investigations, while planning of small-scale flood defenses would demand more detailed model set-ups, including hydraulic models (Apel et al., 2009a, b).

Of interest is how much the bias correction affects the modelled results. Figure 13 gives a comparison of annual damages for the Rhine in the period 2010 to 2100, driven by REMO (left) and CCLM (right) climate (Scenario A1B). The comparison indicates that the damages simulated under CCLM climate are much higher without bias correction, while the simulations driven by REMO give a lower bias, a result which is in line with the observation that the bias in precipitation is larger in CCLM simulations.

Alternate approaches to bias correction can be envisaged, for example using a model system combining hydrological and hydraulic models (in space and time) for all 3766 river sections in Germany and bias corrected climate input data and the same damage model. However, such a set-up would be computationally much more demanding (especially the hydraulic model) and also the data need would rise significantly, whereby some of necessary additional data are not available with the sufficient quality (e.g., cross-sections of all river reaches for the hydraulic model). In addition, the accuracy of bias correction of the climate data and calibration of the hydrological model would be very important as very certain flood levels would have to be reproduced. When using the methodology described here most of these problems can be avoided while giving robust and consistent results for the original problem, to investigate the possible trends in flood hazard and damages in Germany considering climate trends only.

\section{Summary and conclusions}

The study presents a modelling concept suitable for estimating large scale flood damages in future climate scenario conditions, under the assumption of ceteris paribus (other factors unchanged). The central idea is to use extreme value statistics to link hydrological information (on river discharge and its frequency characteristics) and flood loss information. The advantage of the specific approach is that no bias correction for the climate data are needed, hence the approach can be extended to other climate scenarios without the need to conduct the very problematic and time-consuming bias correction of climate input data. Future discharges, corresponding to future climate, are compared with present return periods and with present damage functions. 

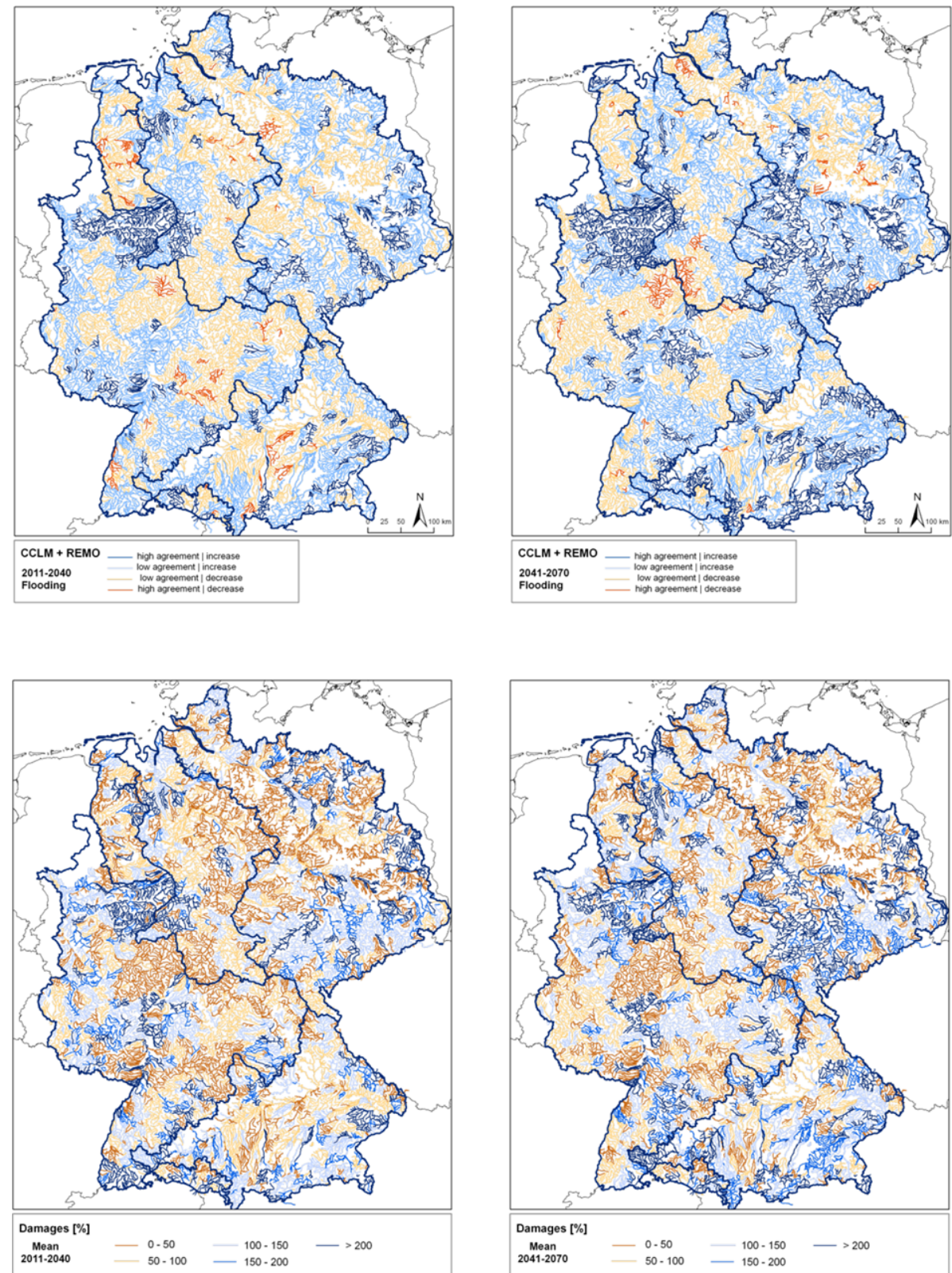

Figure 12. Maps of the changes in flood hazard (upper part) and related losses (lower part), averaged over all scenarios and realizations, for the period 2011-2040 (left) and 2041-2070 (right). High agreement: at least six realizations show the same trend direction; low agreement: at least four realizations show the same trend direction. The damages are shown as relative changes in percent compared with the reference period 1961-2000 (damages of the reference period equal 100\%).

The quantitative results of the study indicate that flood losses are likely to increase significantly under climate change in Germany. Almost all scenarios and realizations investigated show an increase of losses considering the current value of assets until the mid-21st century, whereby the uncertainty is high. This is in accordance with the physically based observation that the warming will also lead to an increase of water-vapour content in the air and hence more intense rain and flood events. The trend and range of future damages is also in line with the ones published by Feyen et al. (2008) for the European scale and the ones of Te Linde et al. (2011) for the Rhine basin, albeit applying different scenario data and in the case of Te Linde et al. (2011) also considering land use changes. 

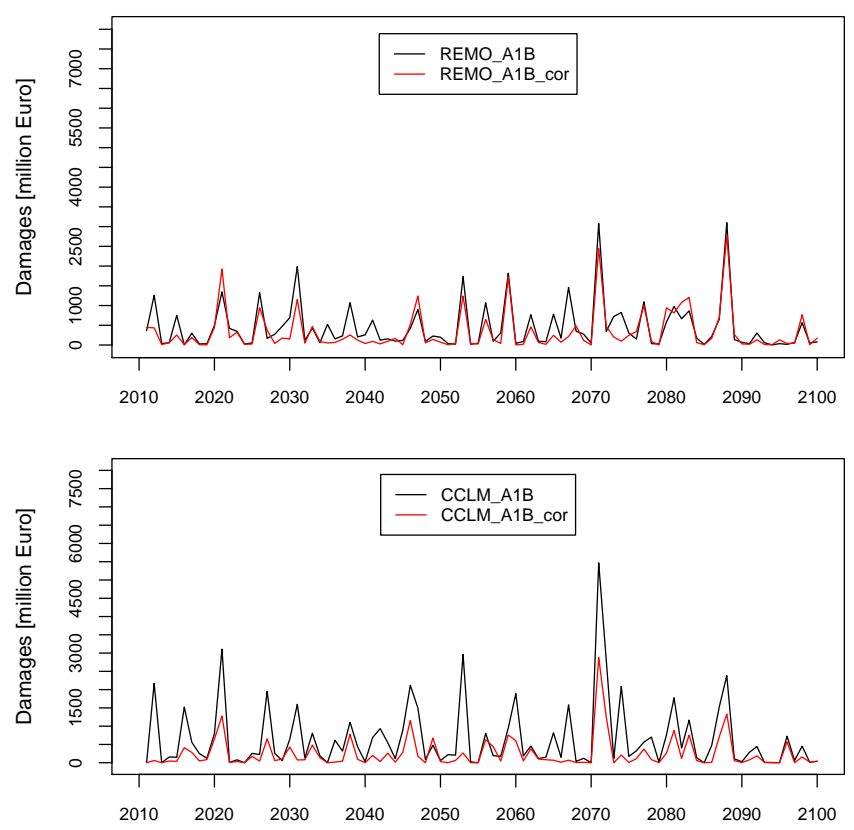

Figure 13. The annual flood damages simulated with and without bias correction in the Rhine basin.

However, the trends in river discharge are not spatially homogenous and show a pattern where sub-basins located in mountainous areas (and there especially the western ranges) often generate increasing flood discharges, while lowland tributaries often show a decrease of flood discharges.
In summary, the hypothesis that climate change will result in more hydrological extremes and higher damages is generally supported by the model-based results presented in this study, although additional investigations are necessary to improve the robustness of the results and to reduce the uncertainty, for example by increasing the set of climate projections including additional combinations of GCMs and $\mathrm{RCMs}$, and/or by considering non-climatic factors, such as changes in the value of assets or regional impacts of large scale flood protection measures. It is worth mentioning that the total economic losses can be, depending on the region and flood event, essentially higher than the damages on buildings and small enterprises considered in this study (cf. Meyer et al., 2013). 


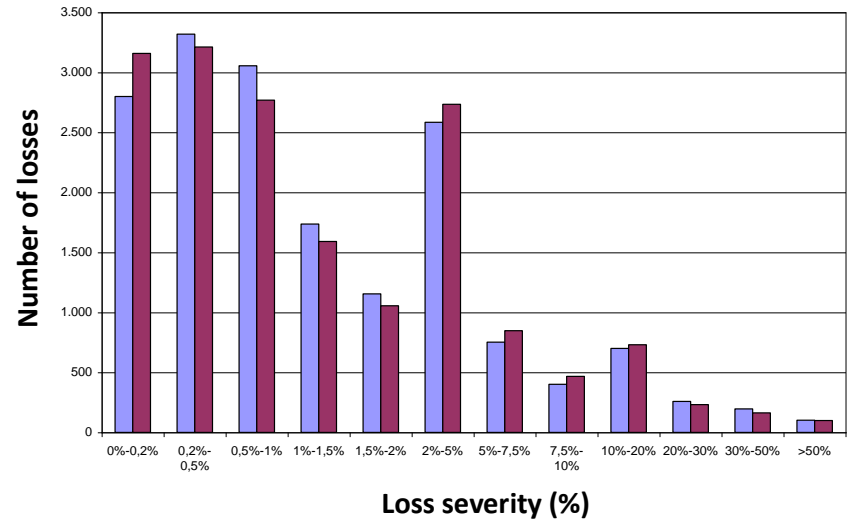

Figure A1. Comparison of simulated and observed number of losses classified by loss severity.

\section{Appendix A: Short description of HQ Kumul and actuarial evaluation}

\section{A1 HQ Kumul}

HQ Kumul is a stochastic generator to create event-related flood runoff along the $55000 \mathrm{~km}$ of the so-called "ZÜRS" hydrological network of medium and large rivers in Germany (identified in the framework of the project ZÜRS). For the same river network, event-related inundation areas are determined, forming the basis for river reach/zip code area specific damage functions (see www.zuers-public.de).

The classical way to identify sets of spatially distributed, event-related floods is to feed simulated or observed rainfall into a rainfall-runoff model and to translate the weather data into related river runoff and floods. HQ Kumul pursued in this context an alternative way in which observed river runoff at gauging stations is used directly (Willems, 2005) to generate flood runoff for the entire river network. To do this, firstly multiple partial flood series for a larger number of gauging locations, spread all over Germany, are simulated. The multiple partial series contain the 100 largest historical flood events in Germany of the period 1961 to 2002. A common, high-dimensional, multivariate probability distribution that describes the marginal distributions of the individual series as well as the correlation structure between the series in sufficient quality is adjusted for this series. On the basis of the high-dimensional probability distribution, three sets of synthetic flood events (10000 each), are generated by means of gauge station-based Monte Carlo simulation. A specially designed geo-statistical interpolation technology, backed with hydrological information, transmitted the station-related results of the Monte-Carlo simulation to the Germany-wide ZÜRS river network.

The ZÜRS inundation areas are the result of onedimensional, stationary hydraulic simulations along the ZÜRS river network adjusted for available water management data. The flood statistics (percentiles) used as input data for various return periods were derived by means of local extreme value analysis of annual flood discharge series for a variety of locations and transferred to the river network.

Finally, for each synthetic HQ Kumul event and each postal code, corresponding flood return periods as well as inundation areas in settlements are derived by overlaying ZÜRS inundation areas with postcode areas including data on built-up areas and settlements. The resulting event matrix represents the basis for further calculations of accumulated losses and return periods.

\section{A2 Actuarial evaluation}

Based on the hydrological processing of historical events (per ZIP code, return period, and related flooded settlement area) comparisons were made with the loss records. Thereby factors influencing the losses, corrected for deductibles, are identified: value of the object (insured sum) and the return period. Then, a log-normal distribution is fitted to the damages taking into account these factors. In result, a good agreement of number of losses and loss severity is obtained, as shown in Fig. A1.

Loss values for each historical event and for each postal zone can be estimated using the hydrological information of the event matrix and the actuarial data adjusted for insured losses. Integration of all postal zones gives the expected loss expense per single flood event, and a loss distribution can be created from all 10000 simulated events. It is assumed that 10000 events represent a period of 4300 years - corresponding to the 100 events from 43 observed years described above. Thus, accumulated losses for specific return periods can be estimated for any stocks.

Under assumption that all residential and smaller commercial buildings have flood insurance, a German-wide maximal insurance sum of EUR 9.1 trillion is determined. Finally, several tests have been carried out to check the plausibility of the results. They have shown a consistent image. For example, the results can be aggregated for region represented by the first number of the zip code and regional characteristics are visible. For example, the 6xxxx postcode area is located along the Rhine and Main rivers. It is heavily populated and thus characterized by the high value of assets. The postcode area $2 \mathrm{xxxx}$ is characterized by lowlands of the rivers Elbe, Ems and Weser. Here, the riverine land is protected by relatively high levees so that significant damage occurs only with higher return periods. 
Acknowledgements. We thank the German Insurance Association for provision of damage functions, Munich RE, Deutsche Rück, Swiss Re, AllianzSE, Nürnberger Beteiligungsgesellschaft and Provinzial Rheinland Versicherung AG, for support and cooperation, especially Thomas Bistry of the Deutsche Rück and Eberhard Faust of the Munich Re. We also thank the German Weather Service and the German Federal Institute of Hydrology for making available basic climate and runoff data. Useful reviews, in the constructive criticism spirit, have helped the authors to improve the contents of the paper, its components and clarity.

Edited by: F. Castelli

Reviewed by: H. Apel and one anonymous referee

\section{References}

Apel, H., Aronica, G., Kreibich, H., and Thieken, A.: Flood risk analyses - how detailed do we need to be?, Nat. Hazards, 49, 79-98, 2009a.

Apel, H., Merz, B., and Thieken, A.: Influence of dike breaches on flood frequency estimation, Comput. Geosci., 35, 907-923, 2009b.

Arnell, N.: The effect of climate change on hydrological regimes in Europe: a continental perspective, Global Environ. Chang., 9, 5-23, 1999.

Arnold, J. G.: ROTO - a continuous water and sediment routing model, in: Watershed Planning and Analysis in Action, ASCE, Durnago, 580-590, 1990.

Becker, A. and Grünewald, U.: Flood risk in central Europe, Science, 300, 1099-1099, 2003.

Berz, G.: Versicherungsrisiko Klimawandel, Promet Verlag, Offenbach a. M., 34, 3-9, 2008.

Böhm, U., Kücken, M., Ahrens, W., Block, A., Hauffe, D., Keuler, K., Rockel, B., and Will, A.: CLM-the climate version of LM: brief description and long-term applications, COSMO Newsletter, 6, 225-235, 2006.

Burghoff, O.: Bewertungsmöglichkeiten von Überschwemmungskumulen mittels HQ Kumul., Presentation at the 58. converence of the German ASTIN Group, Munich, 17. November 2008 .

Cammerer, H., Thieken, A. H., and Lammel, J.: Adaptability and transferability of flood loss functions in residential areas, Nat. Hazards Earth Syst. Sci., 13, 3063-3081, doi:10.5194/nhess-133063-2013, 2013.

Coles, S., Bawa, J., Trenner, L., and Dorazio, P.: An introduction to statistical modeling of extreme values, Springer, London, Berlin, Heidelberg, Vol. 208, 2001.

Dankers, R. and Feyen, L.: Flood hazard in Europe in an ensemble of regional climate scenarios, J. Geophys. Res.-Atmos., 114, 116, doi:10.1029/2008JD011523, 2009.

Dankers, R., Feyen, L., and Christensen, O. B.: On the benefit of high-resolution climate simulations in impact studies of hydrological extremes, Hydrol. Earth Syst. Sci. Discuss., 6, 25732597, doi:10.5194/hessd-6-2573-2009, 2009.

Dollinger, F. and Strobl, J.: Angewandte Geographische Informationsverarbeitung VIII, Salzburger Geographische Materialien, Salzburg, 24, 1996.

Donat, M. G., Pardowitz, T., Leckebusch, G. C., Ulbrich, U., and Burghoff, O.: High-resolution refinement of a storm loss model and estimation of return periods of loss-intensive storms over Germany, Nat. Hazards Earth Syst. Sci., 11, 2821-2833, doi:10.5194/nhess-11-2821-2011, 2011.

Dumas, P., Hallegatte, S., Quintana-Seguì, P., and Martin, E.: The influence of climate change on flood risks in France - first estimates and uncertainty analysis, Nat. Hazards Earth Syst. Sci., 13, 809-821, doi:10.5194/nhess-13-809-2013, 2013.

DVWK: Ermittlung der Verdunstung von Land-und Wasserflächen, Merkblätter, Kommissionsvertrieb Wirtschafts-und Verlagsgesellschaft Gas und Wasser mbH, Bonn, 238, 1996.

Eisenreich, S.: Climate change and the European water dimension, Tech. rep., European Commission - Joint Research Centre, Ispra, Italy, 2005.

Feyen, L., Barredo, J., and Dankers, R.: Implications of global warming and urban land use change on flooding in Europe, in: Water and Urban Development Paradigms. Towards an Integration of Engineering, Design and Management Approaches, Taylor \& Francis Group, London, 217-225, 2008.

GDV: HQ Kumul - Ein vom GDV entwickeltes Tool zur individuellen Abschätzung des Gefährdungspotentials eines Versicherungsbestandes durch Überschwemmungen, Gesamtverband der Deutschen Versicherungswirtschaft GDV, Berlin, 2009.

GDV: Yearbook of the German Insurance Industry 2010, available at: http://www.gdv.de/wp-content/uploads/2011/11/GDV_ Yearbook_2010.pdf, 2010.

Hattermann, F. F., Krysanova, V., Wechsung, F., and Wattenbach, M.: Integrating groundwater dynamics in regional hydrological modelling, Environ. Modell. Softw., 19, 1039-1051, 2004.

Hattermann, F., Wattenbach, M., Krysanova, V., and Wechsung, F.: Runoff simulations on the macroscale with the ecohydrological model SWIM in the Elbe catchment-validation and uncertainty analysis, Hydrol. Process., 19, 693-714, doi:10.1002/hyp.5625, 2005.

Hattermann, F., Krysanova, V., Habeck, A., and Bronstert, A.: Integrating wetlands and riparian zones in river basin modelling, Ecol. Model., 199, 379-392, 2006.

Hattermann, F. F., Gömann, H., Conradt, T., Kaltofen, M., Kreins, P., and Wechsung, F.: Impacts of global change on waterrelated sectors and society in a trans-boundary central European river basin - Part 1: project framework and impacts on agriculture, Adv. Geosci., 11, 85-92, doi:10.5194/adgeo-11-85-2007, 2007.

Hattermann, F. F., Krysanova, V., Post, J., Dworak, T., Wrobel, M., Kadner, S., and Leipprand, A.: Understanding consequences of Climate Change for Water resources and water-related sectors in Europe, in: The Adaptiveness of IWRM, an Analysis of European IWRM Research, IWA Publishing, London, UK, 89-112, 2008a.

Hattermann, F. F., Post, J., Krysanova, V., Conradt, T., and Wechsung, F.: Assessment of water availability in a Central-European River Basin (Elbe) under climate change, Adv. Clim. Change Res., 4, 42-50, 2008b.

Hattermann, F. F., Weiland, M., Huang, S., Krysanova, V., and Kundzewicz, Z. W.: Model-supported impact assessment for the water sector in Central Germany under climate change - a case study, Water Resour. Manag., 25, 3113-3134, 2011. 
Hattermann, F. F., Kundzewicz, Z. W., Huang, S., Vetter, T., Kron, W., Burghoff, O., Merz, B., Bronstert, A., Krysanova, V., and Gerstengabe, F.-W.: Flood risk in holistic perspective observed changes in Germany, in: Changes in Flood Risk in Europe, vol. Special Publication No. 10, IAHS Press, Wallingford, Oxfordshire, UK, 212-237, 2012.

Held, H., Gerstengarbe, F.-W., Pardowitz, T., Pinto, J., Ulbrich, U., Born, K., Donat, M., Karremann, M., Leckebusch, G., Ludwig, P., Nissen, K., Österle, H., Prahl, B., Werner, P., Befort, D., and Burghoff, O.: Projections of global warming-induced impacts on winter storm losses in the German private household sector, Clim. Change, 121, 195-207, doi:10.1007/s10584-0130872-7, 2013.

Helms, M., Buchele, B., Merkel, U., and Ihringer, J.: Statistical analysis of the flood situation and assessment of the impact of diking measures along the Elbe (Labe) river, J. Hydrol., 267, 94 $114,2002$.

Hollweg, H., Böhm, U., Fast, I., Hennemuth, B., Keuler, K., Keup-Thiel, E., Lautenschlager, M., Legutke, S., Radtke, K., Rockel, B., Schubert, M., Will, A., Woldt, M., and Wunram, C.: Ensemble simulations over Europe with the regional climate model CLM forced with IPCC AR4 global scenarios, Tech. rep., Deutsches Klimarechenzentrum, Hamburg, 2008.

Huang, S., Hesse, C., Krysanova, V., and Hattermann, F.: From meso-to macro-scale dynamic water quality modelling for the assessment of land use change scenarios, Ecol. Model., 220, 25432558, 2009.

Huang, S., Krysanova, V., Österle, H., and Hattermann, F. F.: Simulation of spatiotemporal dynamics of water fluxes in Germany under climate change, Hydrol. Process., 24, 3289-3306, doi:10.1002/hyp.7753, 2010.

Huang, S., Hattermann, F. F., Krysanova, V., and Bronstert, A.: Projections of climate change impacts on river flood conditions in Germany by combining three different RCMs with a regional eco-hydrological model, Clim. Change, 116, 631-663, 2013.

Huang, S., Krysanova, V., and Hattermann, F. F.: Does bias correction increase reliability of flood projections under climate change? A case study of large rivers in Germany, Int. J. Climatol., doi:10.1002/joc.3945, online first, 2014.

IPCC: Climate Change 2013: The Physical Science Basis - Summary for Policymakers. Contribution of Working Group I to the Fifth Assessment Report of the Intergovernmental Panel on Climate Change, Intergovernmental Panel on Climate Change, IPCC Secretariat, Cambridge University Press, Cambridge, United Kingdom and New York, NY, USA, 2013.

Jarvis, A., Reuter, H., Nelson, A., and Guevara, E.: Hole-Filled Seamless SRTM Data (online) V4, International Centre for Tropical Agriculture (CIAT), available at: http://srtm.csi.cgiar. org (last access: 14. October 2014), 2008.

Jonkman, S., Bockarjova, M., Kok, M., and Bernardini, P.: Integrated hydrodynamic and economic modelling of flood damage in the Netherlands, Ecol. Econ., 66, 77-90, doi:10.1016/j.ecolecon.2007.12.022, 2008.

Kropp, J. and Schellnhuber, H.: In Extremis: Disruptive Events and Trends in Climate and Hydrology, Springer, Heidelberg, 2010.

Krysanova, V., Müller-Wohlfeil, D., and Becker, A.: Development and test of a spatially distributed hydrological water quality model for mesoscale watersheds, Ecol. Model., 106, 261-289, 1998.
Krysanova, V., Wechsung, F., Arnold, J., Srinivasan, S., and Williams, J.: SWIM (Soil and Water Integrated Model), User Manual, PIK, Potsdam, pik report nr. 69 Edn., available at: http://www.pik-potsdam.de/research/publications/pikreports/ .files/pr69.pdf (last access: 14. October 2014), 2000.

Krysanova, V., Hattermann, F. F., and Wechsung, F.: Process-based ecohydrological modelling at the river basin scale and options for regionalisation, in: Integrated assessment and decision support, Proc. of the 1st biennial meeting of the Int. Env. Modelling and Software Society, edited by: Rizzoli, A. and Jakeman, A., University of Lugano, Switzerland, 24-27 June 2002, Vol. 1, 393 399, 2002.

Kundzewicz, Z. and Schellnhuber, H.: Floods in the IPCC TAR perspective, Nat. Hazards, 31, 111-128, 2004.

Kundzewicz, Z. W., Kanae, S., Seneviratne, S. I., Handmer, J., Nicholls, N., Peduzzi, P., Mechler, R., Bouwer, L. M., Arnell, N., Mach, K., Muir-Wood, R., Brakenridge, G. R., Krono, W., Benito, G., Honda, Y., Takahashi, K., and Sherstyukov, B.: Flood risk and climate change: global and regional perspectives, Hydrolog. Sci. J., 59, 1-28, doi:10.1080/02626667.2013.857411, 2014.

Leander, R., Buishand, T. A., van den Hurk, B. J., and de Wit, M. J.: Estimated changes in flood quantiles of the river Meuse from resampling of regional climate model output, J. Hydrol., 351, 331343, 2008.

Lehner, B., Doll, P., Alcamo, J., Henrichs, T., and Kaspar, F.: Estimating the impact of global change on flood and drought risks in europe: a continental, integrated analysis, Clim. Change, 75, 273-299, doi:10.1007/s10584-006-6338-4, 2006.

Leipprand, A., Dworak, T., Benzle, M., Berglund, M., Kadner, S., Hattermann, F., Post, J., and Krysanova, V.: Impacts of climate change on water resources: adaption strategies for Europe, Tech. rep., German Federal Environment Agency, available at: http://www.tnc-cc-eeaa-eg.com/Pics/dwnld290.pdf (24. October 2014), 2008.

Maidment, D.: Handbook of Hydrology, McGraw-Hill Inc., New York, 1993.

Menzel, L. and Burger, G.: Climate change scenarios and runoff response in the Mulde catchment (Southern Elbe, Germany), J. Hydrol., 267, 53-64, 2002.

Merz, B. and Thieken, A. H.: Flood risk curves and uncertainty bounds, Nat. Hazards, 51, 437-458, doi:10.1007/s11069-0099452-6, 2009.

Merz, B., Kreibich, H., and Lall, U.: Multi-variate flood damage assessment: a tree-based data-mining approach, Nat. Hazards Earth Syst. Sci., 13, 53-64, doi:10.5194/nhess-13-53-2013, 2013.

Meyer, V., Becker, N., Markantonis, V., Schwarze, R., van den Bergh, J. C. J. M., Bouwer, L. M., Bubeck, P., Ciavola, P., Genovese, E., Green, C., Hallegatte, S., Kreibich, H., Lequeux, Q., Logar, I., Papyrakis, E., Pfurtscheller, C., Poussin, J., Przyluski, V., Thieken, A. H., and Viavattene, C.: Review article: Assessing the costs of natural hazards - state of the art and knowledge gaps, Nat. Hazards Earth Syst. Sci., 13, 1351-1373, doi:10.5194/nhess-13-1351-2013, 2013.

MunichRe: Weather Catastrophes and Climate Change. Is there still Hope for Us?, Knowledge series, Munich Re (Münchener Rückversicherungsgesellschaft), Munich, 2005.

Nakićenović, N. and Swart, R.: Summary for Policymakers: Emission Scenarios: a Special Report of Working Group III of the Intergovernmental Panel on Climate Change, Intergovernmental 
Panel on Climate Change, Cambridge University Press, Cambridge, 2000.

Petrow, T. and Merz, B.: Trends in flood magnitude, frequency and seasonality in Germany in the period 1951-2002, J. Hydrol., 371, 129-141, doi:10.1016/j.jhydrol.2009.03.024, 2009.

Piani, C., Weedon, G., Best, M., Gomes, S., Viterbo, P., Hagemann, S., and Haerter, J.: Statistical bias correction of global simulated daily precipitation and temperature for the application of hydrological models, J. Hydrol., 395, 199-215, doi:10.1016/j.jhydrol.2010.10.024, 2010.

Ritchie, J.: Model for predicting evaporation from a row crop with incomplete cover, Water Resour. Res., 8, 1204-1213, 1972.

Röckner, E., Bengtsson, L., Feichter, J., Lelieveld, J., and Rodhe, H.: Transient climate change simulations with a coupled atmosphere-ocean GCM including the tropospheric sulfur cycle, J. Climate, 12, 3004-3032, 1999.

Röckner, E., Buml, G., Bonaventura, L., Brokopf, R., Esch, M., Giorgetta, M., Hagemann, S., Kirchner, I., Manzini, L., Rhodin, A., Schlese, U., Schulzweida, U., and Tompkins, A.: The Atmospheric General Circulation Model ECHAM5: Part 1: Model Description, Tech. rep., Max-Planck-Institute for Meteorology, Hamburg, Germany, 2003.

Seneviratne, S. I., Nicholls, N., Easterling, D., Goodess, C., Kanae, S., Kossin, J., Luo, Y., Marengo, J., McInnes, K., Rahimi, M., Reichstein, M., Sorteberg, A., Vera, C., and Zhang, $\mathrm{X}$.: Changes in climate extremes and their impacts on the natural physical environment, in: Managing the Risks of Extreme Events and Disasters to Advance Climate Change Adaptation, A Special Report of Working Groups I and II of the Intergovernmental Panel on Climate Change (IPCC), Intergovernmental Panel on Climate Change (IPCC), Cambridge University Press, Cambridge, UK, and New York, NY, USA, 109-230, 2012.

Smedema, L. K. and Rycroft, D. W.: Land Drainage: Planning and Design of Agricultural Systems, Vol. 376, Cornell University Press, Ithaca, New York, 1983.
Statistisches Bundesamt (Ed.): Statistisches Jahrbuch für die Bundesrepublik Deutschland, Metzler/Poeschel-Verlag, Wiesbaden, 2008.

te Linde, A. H., Bubeck, P., Dekkers, J. E. C., de Moel, H., and Aerts, J. C. J. H.: Future flood risk estimates along the river Rhine, Nat. Hazards Earth Syst. Sci., 11, 459-473, doi:10.5194/nhess-11-459-2011, 2011.

Thieken, A., Müller, M., Kreibich, H., and Merz, B.: Flood damage and influencing factors: new insights from the August 2002 flood in Germany, Water Resour. Res., 41, 1-16, doi:10.1029/2005WR004177, 2005.

Tomassini, L. and Jacob, D.: Spatial analysis of trends in extreme precipitation events in high-resolution climate model results and observations for Germany, J. Geophys. Res.-Atmos., 114, 1-20, 2009.

Tu, M., Hall, M., de Laat, P., and de Wit, M.: Extreme floods in the Meuse river over the past century: aggravated by land-use changes?, Phys. Chem. Earth, 30, 267-276, doi:10.1016/j.pce.2004.10.001, 2005.

Varis, O., Kajander, T., and Lemmelä, R.: Climate and water: from climate models to water resources management and vice versa, Clim. Change, 66, 321-344, 2004.

Wilby, R., Hay, L., and Leavesley, G.: A comparison of downscaled and raw GCM output: implications for climate change scenarios in the San Juan River basin, Colorado, J. Hydrol., 225, 67-91, 1999.

Willems, W.: 10000 Hochwasserereignisse - synthetisch generiert, VersicherungsWirtschaft, 60, 683-684, 2005.

Willems, W.: PLZ-Zuordnung der Teileinzugsgebiete des UBAFlächenverzeichnisses für Deutschland, Potsdam-Institut für Klimafolgenforschung (PIK), Potsdam, 2010.

Wood, A., Leung, L., Sridhar, V., and Lettenmaier, D.: Hydrologic implications of dynamical and statistical approaches to downscaling climate model outputs, Clim. Change, 62, 189-216, 2004. 